Sharif University of Technology
Scientia Iranica
SCIENTIA
I RAN I C A

\title{
Assessment of collapse modes in reinforced concrete frames considering record-to-record and modeling uncertainties
}

\author{
E. Tafakori ${ }^{\mathrm{a}}$, S. Pourzeynali ${ }^{\mathrm{a}, *}$ and H.E. Estekanchi ${ }^{\mathrm{b}}$ \\ a. Department of Civil Engineering, Engineering Faculty, University of Guilan, Rasht, P.O. Box 41635-3756, Iran. \\ b. Department of Civil Engineering, Sharif University of Technology, Tehran, P.O. Box 11155-9313, Iran.
}

Received 28 June 2015; received in revised form 14 May 2016; accepted 2 July 2016

\author{
KEYWORDS \\ Concrete moment \\ frame; \\ Collapse modes; \\ Uncertainties; \\ Performance- \\ based earthquake \\ engineering; \\ Incremental dynamic \\ analysis.
}

\begin{abstract}
Dominant Collapse Mechanisms (DCMs) have been reported to play an important role in collapse capacity of structural systems and the seismic losses consequent to it. Therefore, DCMs of Reinforced Concrete (RC) frames have been studied, in this article, considering Record-To-Record (RTR) and modeling uncertainties. Two sets of RC frames have been designed, in this regard, that share the design assumptions but contain different levels of over-strength. Each set contains 26, 4- to 20-story nonlinearly modeled frames. Initially, Incremental Dynamic Analysis (IDA) was used to identify frames' DCMs. Then, the RTR variability reflected through IDA was combined with spectral shape and pulse effects of the ground motion records. Modeling uncertainties were finally introduced to the study using a response surface based Monte Carlo method. The study results revealed that the degree to which DCMs were affected by the associated uncertainties was a function of the over-strength provided to the frames. This effect is found to be generally important and particularly remarkable for especially detailed ductile structures.
\end{abstract}

(C) 2017 Sharif University of Technology. All rights reserved.

\section{Introduction}

Failure of the members in a structural frame may lead to different consequences regarding the configuration of the structure. In a determinate structural system, where redundancy is equal to zero, an immediate collapse is expected to occur. Existence of redundant strength providers will, however, lead to partial and local weakening of the system. The latter is the case for the majority of practical structures and system collapse normally takes place after an adequate number

\footnotetext{
*. Corresponding author. Tel.: +9813 33690270

E-mail addresses: ehsan.tafakori@gmail.com (E. Tafakori); pourzeynali@guilan.ac.ir (S. Pourzeynali); stekanchi@sharif.edu (H.E.Estekanchi)
}

doi: $10.24200 /$ sci. 2017.4156 of plastic mechanisms are formed. Lateral instability of structural frames, or the so-called sidesway collapse, is dominated by secondary effects of gravitational forces. That is, the primary internal actions caused by the inertia (seismic) forces are not normally of an order to drive the system into sidesway collapse. But, multiplying the gravitational forces by the lateral displacements yields in secondary overturning moments, which are responsible for the collapse of the system. Still, this would hardly cause system failure in absence of behavior nonlinearity, which is economically unavoidable during an extreme event. A nonlinear structure normally loses stiffness at increased deformations. Such softening causes the lateral displacements to grow at an accelerated rate, which eventually governs the system failure. Distribution of plastic, or softened, regions throughout the structure can follow different patterns. A local plasticity is concentration of deformations in 
a limited area of structure as a result of inappropriate proportioning of the members. Commonly, such localization prevents nonlinear behavior from spreading all over the structure, which is called a total plasticity. At a total plasticity, a rather uniform distribution of nonlinearity is obtained for all parts of the structure and the plastic deformation capacity of the members is exploited well. Although a total plasticity is generally preferred over a local one, sometimes it can be hardly obtained under a real seismic event. Under some circumstances, such as a "series" system subjected to an imposed displacement, when yielding of a member precedes that of the others, the softened behavior of the member elevates its potential for absorbing the imposed deformations. Therefore, by continuing the excitation, the yielded element develops plasticity even further while other members are still in elastic range. Complex structural systems are always a combination of "series" and "parallel" systems. A proper configuration of members well-proportioned against the expected loads will shield the structure form local plastic regions. Even in case of formation, the destruction potential of local mechanisms depends on geometry and configuration of the structure.

A multi-story structure can be regarded as a "series" collection of stories. From this point of view, each story is treated as a resisting unit of structure, which is itself a collection of some members. Sum of interstory deformations makes up the total deformation induced in a structure in response to an applied base shear. Therefore, softening of a story sooner than the others might yield in a local story mechanism as in a "series" system. Excessive deformation localized at one or more stories will eventually govern the collapse of a structural system. Such combination of story mechanisms is called Dominant Collapse Mechanism (DCM).

Analytically speaking, the ground motion intensity which a structure can sustain before collapse occurrence is called Seismic Collapse Capacity (SCC). Even for a constant structural configuration, changing the applied ground motion may lead to a change in the DCM. This alteration is usually accompanied by a change in the SCC and a correspondence can be assumed between SCC and DCM values. To equip a building with sufficient SCC, as is intended by seismic building codes, avoiding the unwanted DCMs and providing for the others can be effective. The success of seismic codes in reaching this goal needs to be evaluated and has been addressed in the past research.

Takizawa and Jeannings proposed a numerical approach for modeling the dynamic process of failure for Reinforced Concrete (RC) moment frames [1]. They contended that there was a strong dependency between collapse probability and shape of the mechanism that dominated the behavior during the critical displace- ment cycle. They also stated that the collapse mechanism could be reasonably identified using a pushover analysis with an appropriately selected lateral load distribution.

Bernal presented a method for checking the safety of two-dimensional buildings against dynamic instability [2]. They expressed that the minimum design base shear needed to assure collapse prevention against a given ground motion and was strongly dependent on the shape of the controlling mechanism.

Banazadeh and Fereshteh Nejad used a Baysian network to derive probabilistic correlations between potential collapse mechanisms and collapse occurrence [3]. They used static pushover analyses with varying load patterns to identify likely collapse mechanisms, which were defined as a combination of plastic hinges forming at various locations throughout the structure [3].

FEMA p695 guideline considers different collapse scenarios (mechanisms) and studies their correlation with the estimated collapse capacity of the buildings [4]. This guideline also states that for ductile structures, a fewer number of mechanisms are likely to dominate structural collapse.

A recent seismic code, which uses probability of the collapse mechanisms as a tool for estimating seismic casualty losses, is ATC 58 [5]. A collapse mechanism is defined by this code as a specific story in which nonlinear lateral drift has been maximized. This definition follows a macro approach that focuses on the resultant deformation concentration in stories rather than on the local plasticity in the members. In the current study, collapse mechanisms are defined following ATC 58 method, which is further described in the upcoming sections.

Numerical evaluation of buildings' seismic performance is affected by Record-To-Record (RTR) and modeling uncertainties.

The RTR variability is a result of the inherent randomness of earthquake hazard and can be addressed using Incremental Dynamic Analysis (IDA) [6]. The variability of ground motions frequency content is addressed in IDA by using a rather large number of records. Each record is then incrementally scaled to multiple intensity levels and the structural response is simulated at each level. The intensity of ground motions is expressed in terms of an appropriate measure called Intensity Measure (IM). The IM value corresponding to collapse state is extracted for each record within IDA. The distribution of IM values obtained for different records at collapse or intermediate response levels is assessed for reflecting RTR variability. Modeling uncertainties refer to the variability of stiffness, strength, and ductility of structural members as well as building dynamic characteristics such as mass and damping distribution. Detailed description of the used 
method including modeling uncertainties is provided in Section 6.

Some studies (e.g., [7,8]) have revealed that ground motion characteristics like elastic spectrum shape and pulse-like index have an effect on nonlinear behavior of structures. Although some of these results have been concluded for near-field ground motions, they can also be true for far-field ground motions. Porter showed that uncertainties associated with modeling the mass and damping properties did not remarkably affect seismic performance predictions of structures [9]. Liel et al. investigated collapse capacity of RC frames considering modeling uncertainties associated with strength and ductility of structural members [10]. They used a Response Surface-based Monte Carlo (RSMC) approach and the simpler First Order Second Moment (FOSM) reliability method for reflecting the modeling uncertainties. Introducing the modeling uncertainties to the collapse probability curves through the RSMC method led to a shift in the median of predictions as well as an increase in their dispersion. Nevertheless, using the FOSM for incorporating modeling uncertainties could not simulate the shift of the median predictions. The Liel et al. [10] study and the other assessments conducted following it ( e.g., $[11,12]$ ) have revealed that the effect of modeling uncertainties is more pronounced on structures with lower ductility. Since the RSMC methodology utilized by Liel et al. [10] is also used in the current study, it is further described in Section 6 .

\section{Identification of collapse mechanisms}

As was mentioned in the previous section, a combination of plastic hinges can form a local softened mechanism. Such mechanism might undergo excessive lateral deformations during a severe ground motion. In presence of conventional gravitational forces, such excessive deformation will induce second order instabilities that may eventually lead to structural collapse. However, the past research (e.g. [3,6]) has revealed that in the majority of buildings, formation of local softening in a few stories (or sometime in a single story) dominates dynamic instability followed by collapse. According to this observation, the previous definition given for a plastic mechanism can be revised using a more general and macro definition. Using this definition, a collapse mode is not defined as a combination of "plastic hinges" but as a "story" on which deformation concentrates. By using this definition, redundant "plastic hinge"based definitions that point to softening of the same story are merged and represented by a single storybased mechanism. Attributing structural collapse to story-based mechanisms is a simpler and more direct method. A story-based definition is employed in the performance-based guideline, ATC 58 [5]. In this
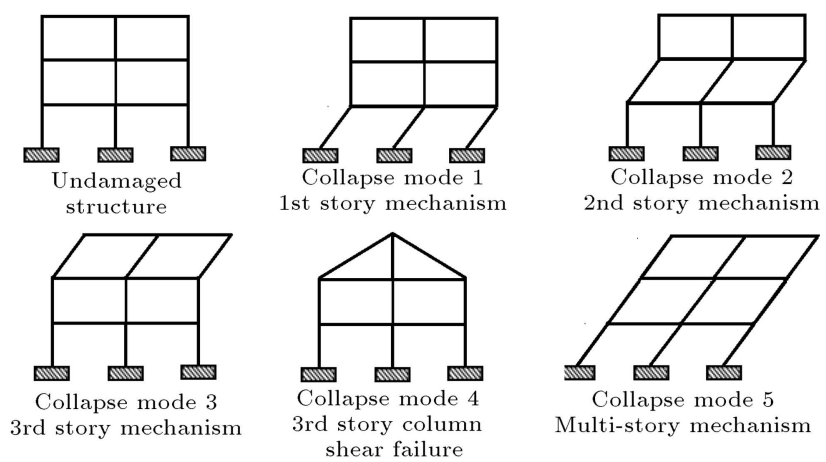

Figure 1. Schematic definition of dominant collapse mechanisms [5].

guideline, the severity of collapse strongly correlates with the controlling collapse mechanism [5]. A collapse mechanism is identified by this code as the story experiencing a maximum drift ratio [5].

In the present article, collapse mechanism is identified using a method similar to ATC 58 [5] guideline. Regarding the story-based definition, a collapse mechanism is identified by the story at which the relative drifts have been maximized during the response history analysis. Regarding this definition, a structure with $n$ number of stories is likely to collapse through $\mathrm{n}$ different collapse modes. An extra mechanism is also defined by ATC 58 [5] as the "overall" mechanism in which all stories undergo a rather uniform distribution of excessive drifts. Since identification of overall collapse mode is based on subjective judgment, it has not been considered in this article. The definition of DCMs used in this article is schematically illustrated in Figure 1.

\section{Collapse detection method}

Numerical identification of collapse occurrence is a challenging issue, which has been differently addressed by various studies and guidelines. Generally, the collapse detection methods can be divided into two categories. The first category uses occurrence of either of mechanical mechanisms considered as collapse symptom. These mechanisms are commonly identified through static pushover analyses with varying lateral load patterns [1]. The second category of collapse detection methods relies on observation of dynamic instability. These methods rely on the ability of the utilized modeling method to reflect formation of plastic mechanisms in dynamic instability of the structure. The first group of detection methods requires a complicated numerical manipulation of response data. On the other hand, the second is addressed straightly by reliance on a model in which behavior deterioration is effectively reflected. This detection method is employed by recent guidelines such as FEMA p695 [4] and ATC 58 [5]. 
The criterion used by these guidelines for numerical identification of dynamic instability employs Incremental Dynamic Analysis (IDA) [6]. Following this method, incrementally scaled versions of a ground motion are applied to the structural model. As mentioned, such model must effectively account for expected deformation sources and behavior deterioration during analysis. A curve depicting the ground motion intensity versus the structural response is then extracted. Gradual softening of this curve is considered as a reflection of structural behavior approaching dynamic instability. Reaching a slope limit of $20 \%$ of the initial slope is suggested by FEMA p695 [4] and ATC 58 [5] as dynamic instability criterion. The collapse inducing intensity is represented, in IDA method, in terms of an appropriate Intensity Measure (IM). Also, a suitable Engineering Demand Parameter (EDP) is used for reflecting the structural response.

To account for Record-To-Record (RTR) uncertainties, the collapse capacities against multiple ground motion records are obtained through IDA. Selection of an "efficient" IM can help in reducing the dispersion of the obtained capacity values. A "sufficient" IM is one providing an acceptably complete representation of ground motion characteristics and eliminating the need for extra parameters. The IDA method is used, in this article, for detecting the collapse state and the associated mechanisms dominating it. Also, structural modeling of the studied buildings considers components behavior deterioration.

The IDA data are used for deriving $G(\mathrm{CP} \mid \mathrm{IM}=$ $i m$ ) functions expressing probability of violating the Collapse Prevention (CP) limit state conditioned on the IM values exceeding a specific limit $(=i m)$. These data are also used for extracting the $G$ (DCM $=$ $d c m \mid \mathrm{CP})$ function denoting the probability of observing a specific mechanism $(=\mathrm{dcm})$ provided that a collapse occurrence has been detected. Following the conditional probability theory, the total (non-conditional) probability of observing a specific DCM can be stated as:

$$
\begin{aligned}
G(\mathrm{DCM}=d c m)= & \int_{\mathrm{IM}=0}^{\mathrm{IM}=\infty} G(\mathrm{DCM}=d c m \mid \mathrm{CP}) \\
& \times G(\mathrm{CP} \mid \mathrm{IM}) \times d G(\mathrm{IM})
\end{aligned}
$$

This equation denotes that the two aforementioned conditional probabilities must be multiplied and integrated over the full range of IM occurrence probabilities.

\section{Effect of spectral shape on the likely DCMs}

Some previous research (e.g. [6]) has used first mode spectral acceleration, $S_{a}\left(T_{1}\right)$, as an IM representing ground motion characteristics. Despite the advantages of this IM over other parameters such as peak ground acceleration [6], it suffers the inability to account for the contribution of higher vibration modes. Such consideration becomes necessary when the higher modes are significant. In addition, $S_{a}\left(T_{1}\right)$ parameter does not account for the changes of vibration period resulting from softened dynamic behavior. To account for these issues, more characteristics of the elastic spectrum of a given ground motion must be reflected in the selected IM. Ideally, the shape of the whole spectrum is required for a perfect recognition of ground motion characteristics.

An attempt to provide a better representation of spectrum characteristics is made by introducing the $\varepsilon$ (epsilon) parameter. This parameter presents a local average characteristic shape of the spectrum through Eq. (2):

$$
\varepsilon=\frac{\ln \left(S_{a}\left(T_{1}\right)\right)-\mu \ln \left(\overline{S_{a}\left(T_{1}\right)}\right)}{\sigma \ln \left(\overline{S_{a}\left(T_{1}\right)}\right)} .
$$

In this equation, $\mu$ and $\sigma$ denote, respectively, the median and dispersion of the $\overline{S_{a}\left(T_{1}\right)}$ parameter resulting from attenuation laws. Baker and Cornel [13] showed that ground motion records with similar $S_{a}\left(T_{1}\right)$ values but varying values of the $\varepsilon$ parameter caused different vibrations on the single degree of freedom systems. Therefore, the $G(\mathrm{CP} \mid \mathrm{IM})$ probability function extracted from an IDA process would also be affected by considering the $\varepsilon$ parameter. This parameter is, in turn, expected to affect the DCMs probability studied in this article. Thus, the spectral shape of ground motions will be considered using the $\varepsilon$ parameter in some parts of this article.

\section{Effect of velocity pulse on structural response}

According to the "equal displacement" rule, equal displacements are experienced by linear and nonlinear models having vibration periods that fall in a special range. Pulse-like ground motions, however, have been shown by several studies to violate this rule and impose nonlinear displacements that are remarkably larger than the linear ones. This observation has been made even for periods in which the equal displacement rule is true. A suitable account of this phenomenon in simulating the structural response needs for a proper quantity for identification of the velocity pulse in ground motion records. This quantity was proposed by Baker [14] using wavelet analysis by separating the main pulse from the record and dividing it to the main and remaining signals. Eq. (3), shown in Box I, is proposed by Baker [14] for calculating the pulse index of a ground motion record. 


$$
\mathrm{PI}=\frac{1}{1+\operatorname{EXP}(-23.3+14.6(\mathrm{PGV} \text { Ratio })+20.5(\text { Energy Ratio }))}
$$

In this equation, the $\mathrm{PGV}$ ratio denotes the ratio of the maximum amplitude of the remaining signal to the amplitude of the main signal. The term energy ratio reflects the ratio of the energy of the main signal to that of the remaining signals. The values of this index fall in a zero to one range and the larger they become, the stronger the pulse-like characteristic of the record is.

\section{Quantification of modeling uncertainties through RSMC approach}

Two outcomes are aimed at this study by performing IDA process. The first one is the probability of violating the collapse limit at different IM values. The second is extracting the DCM probabilities at collapse state. A lognormal collapse probability function can be represented completely using a pair of median and standard deviation values. These two values along with the DCMs are designated as the IDA's Target Variables (TVs). The extracted probabilities reflect only the ground motion or record-to-record variability. However, the variability of model characteristics (e.g., members' strength, stiffness, ductility, etc.), which is called modeling uncertainty, must also be included. For this purpose, the RSMC method [10] is utilized in which members' characteristics are reflected through Random Variables (RVs). In reality, the characteristics assigned to each of the members must be subjected to independent variability. However, such treatment of variability could lead to a large number of RVs that could hardly be addressed.

To reduce the number of considered RVs, member characteristics are grouped regarding the member type (i.e., beam or column) they belong to and the behavior aspect (i.e., strength or ductility) they are supposed to reflect. The RVs representing each group of characteristics are assumed to be fully correlated (change concurrently and follow a single probability distribution) and are called Meta Random Variables (MRVs). Doing so, 4 MRVs are defined throughout the structures, which include Column Strength (CS), Column Ductility (CD), Beam Strength (BS), and Beam Ductility (BD). By introducing MRVs, different characteristics (or RVs) falling in a same group and having various medians and standard deviations are mapped to a same MRV. To construct this mapping, a normalized distribution (with median equal to 0 and standard deviation equal to 1 ) is attributed to each
MRV. After generating the value of an MRV, the values related to different members are generated by taking into account its specific median and standard deviation.

The sensitivity of IDA outcomes (target variables, TVs) to the defined MRVs can now be comfortably assessed. In this regard, the MRVs are systematically perturbed several times following the Box-Wilson central composite design method [15] and the IDA process is performed each time. According to Box-Wilson method, the MRVs are perturbed from their median by either 1.7 or 1.2 times their standard deviation. The 1.7 coefficient is used when all MRVs except the one being perturbed are set to their medians. The 1.2 , on the other hand, is used when two or more MRVs are perturbed simultaneously. The data points obtained for each TV using the sensitivity analyses are used, at the next step, for establishing polynomials that correlate the TVs to the MRVs through multivariate regression equations. The obtained polynomial established for a TV is called "response surface" and can reasonably substitute for the IDA for generating the TV values. A Monte Carlo simulation is used, next, for predicting the TVs corresponding to thousands of MRVs generated randomly. The random society generated in this way for the TVs is finally regarded for extracting probabilistic performance quantities in which modeling and Record-To-Record (RTR) uncertainties are combined.

\section{The structural model archetypes}

To obtain results that are generalizable to an acceptably wide range of design decisions, 34 special RC moment frames designed previously by Haselton [16] were considered in this study. These frames were designed in accordance with ACI 318-02 [17] and ASCE 7-02 [18] guidelines and were located on a high seismicity site with $\mathrm{Sm}_{c}=1 \mathrm{~g}$ and $\mathrm{Sm}_{2}=1.5 \mathrm{~g}$. These frames have been used by seismic assessment studies such as FEMA p695 [4] and NIST GCR 11-917-15 report [19]. More details about configuration of the structures can be found elsewhere (e.g. [16]). According to the definition of the DCMs in this article, the one- and two-story buildings did not suit the DCM identification purpose and were omitted. This led the number of structures to decrease to 26. An evaluation of demand-to-capacity ratios of frames showed the presence of some overstrengths that could be released by finer grouping of the members. A group of members shared a section, which had been necessitated for the member with highest 
demand value. The more the number of members in a group, the higher the over-strength provided for the structure. Haselton [16] grouped, for example, the columns of every 10 stories in a 20 -story building and provided a high over-strength in the buildings. On the other hand, increasing the over-strength of members in a story will decrease its potential for dominating the collapse state. This, in turn, leads to a reduction in number of observed DCMs and a decreased sensitivity of DCMs to the studied parameters. To assess this issue, a lower over-strength level was considered in addition to that provided by Haselton frames [16]. For this purpose, a finer member grouping was used and the frames were redesigned by obtaining demand-tocapacity ratios closer to unity.

Much research has validated and improved the nonlinear numerical methods used for modeling behavior of the buildings. Vian and Bruneau [20,21] performed experimental investigations on single-degree-offreedom steel frames. They used the stability coefficient to reflect the significance of the secondary moments induced by gravitational forces. This coefficient was found to leave the most pronounced effect on the maximum relative displacement and collapse-inducing spectral acceleration values. Kanvinde [22] performed numerical analyses of steel frames tested by Vian and Bruneau [20] using OpenSees software [23] that approved the accuracy of the utilized numerical model.

Ibarra et al. [24] developed a hysteresis model for representing cyclic behavior of ductile members. This model accounted for deterioration of strength and stiffness of the components. Zareian and Krawinkler [25] showed the significance of component deterioration in collapse capacity of structural systems. Haselton [16] calibrated the parameters of the Ibarra-Krawinkler hysteresis model to reflect the experimental results obtained for Reinforced Concrete (RC) members.

Two methods (the distributed-plasticity and lumped-plasticity) are commonly utilized for nonlinear modeling of beam-column elements. The distributedplasticity method accounts for partial plasticity within section and element length using fiber method. These elements have been used for damage analysis of RC structures under extreme loading conditions in some research [26-28]. However, the computation cost of this method is high compared to the lumpedplasticity method recommended by FEMA p695 [4] for estimating the collapse capacity, which is described below. Some convergence problems are also faced when tension-cracking of concrete section is to be accounted for. Due to these issues, the distributed-plasticity elements are not used in this article.

The second method is lumped plasticity method in which nonlinear behavior is concentrated at the elements end regions by using inelastic springs. Following this method, a beam-column element is dis- cretized into three elements. The two end springs are connected by an elastic element representing crosssectional properties of the member. Force-deformation relationship used in modeling of these springs must account for section and geometry of the member. Such relationships were proposed by Haselton [16] for $\mathrm{RC}$ members by relying on the Ibarra-Krawinkler [24] hysteresis model. The parameters of this model were calibrated by Haselton [16] to match the experimental results obtained for $\mathrm{RC}$ members. The calibrated data were, then, subjected to multi-variate regression analysis. The outcome was equations that could predict Ibarra-Krawinkler model parameters for various geometries of the beam and column members. These equations are used, in this article, along with the Ibarra-Krawinkler hysteretic material to model RC frames in the two-dimensional models established in OpenSees [23] software. To enable calculation of second-order moments, the P-Delta effects are switched on for column elements. The modeling of beams uses linear transformation, which implies neglect of large deformations.

For performing dynamic analyses, direct integration method was used. Various solution algorithms are available in OpenSees, including Newton-Raphson, Newton-Raphson with initial stiffness, Newton linesearch, Krylov-Newton, etc. A combination of these algorithms with a time-step reduction strategy is used for facilitating convergence. Such combination was achieved by programming the analysis manager file fed into the OpenSees software.

\section{DCM identification results}

The two low- and high-over-strength design sets of the 26 considered buildings were subjected to the IDA procedure using the hunt and fill algorithm [6]. The inter-story drift ratios at the collapse state were considered for identifying the story mechanisms following the DCM definition method presented in Section 2. The DCMs contributing to structural collapse of high-overstrength frames, designed by Haselton [16], involved a few stories in each building. This limitation was attributed to the wide grouping of members. The over-strength provided by member grouping prevented some mechanisms from forming at top stories. The removal of these groupings in the low-over-strength set led, therefore, a more varied range of stories to get involved in the structural collapse. The probability of each DCM conditioned on collapse occurrence is computed through numbering the times the maximum inter-story drift ratio occurs in a specific story. The stories associated with the DCMs and the corresponding probabilities are presented in Table 1 according to the two over-strength levels for buildings with different heights. 
Table 1. Probability of DCMs conditioned on collapse occurrence.

\begin{tabular}{|c|c|c|c|c|c|c|c|c|c|}
\hline \multirow{2}{*}{ Over-strength } & \multirow{2}{*}{$\begin{array}{c}\begin{array}{c}\text { Number of } \\
\text { stories }\end{array} \\
4\end{array}$} & \multicolumn{8}{|c|}{ Probability of DCMs conditioned on collapse } \\
\hline & & Story & 1 & 2 & 3 & 4 & & & \\
\hline \multirow{7}{*}{ Low } & & probability & 0.123 & 0.25 & 0.505 & 0.123 & & & \\
\hline & 8 & Story & 1 & 2 & 3 & 4 & & & \\
\hline & & probability & 0.145 & 0.359 & 0.250 & 0.245 & & & \\
\hline & 12 & Story & 1 & 2 & 3 & 4 & 5 & & \\
\hline & & probability & 0.182 & 0.136 & 0.490 & 0.068 & 0.123 & & \\
\hline & 20 & Story & 1 & 2 & 3 & 4 & 5 & 6 & 9 \\
\hline & & probability & 0.123 & 0.091 & 0.217 & 0.114 & 0.250 & 0.091 & 0.114 \\
\hline \multirow{8}{*}{ High } & 4 & Story & 1 & 2 & 3 & & & & \\
\hline & & probability & 0.182 & 0.773 & 0.0454 & & & & \\
\hline & 8 & Story & 1 & 2 & 3 & & & & \\
\hline & & probability & 0.909 & 0.045 & 0.045 & & & & \\
\hline & 12 & Story & 1 & 2 & 3 & & & & \\
\hline & & probability & 0.563 & 0.123 & 0.314 & & & & \\
\hline & 20 & Story & 1 & 2 & 3 & 4 & 5 & 6 & \\
\hline & & probability & 0.045 & 0.091 & 0.423 & 0.364 & 0.045 & 0.023 & \\
\hline
\end{tabular}

As shown in Table 1, a more uniform distribution of DCM probabilities is observed for low over-strength structures. The inter-story drift ratios experienced at DCM story of the high over-strength buildings are much larger than those of other non-mechanism stories. Formation of an overall collapse was, therefore, very unlikely for this group of buildings. The more uniform distribution of strength over height of the low overstrength buildings shows, however, a more effective contribution of non-mechanism stories. The identification of DCMs is based on the maximum inter-story drift and the stories with drifts close to the maximum value are disregarded. However, such closeness could be accounted for by taking a more qualitative approach using engineering judgment. An approximation shows that such approach, if taken, can classify about $10 \%$ of DCMs as overall mechanism. This method was not, however, used due to its subjective nature. The overall mechanisms were, therefore, neglected and were reported as the DCMs featuring the story in which the inter-story drift was maximized.

The effect of spectral shape of ground motions, described in Section 4, on the observed DCM probabilities is assessed by dividing the applied ground motions into two $\varepsilon>\varepsilon_{\text {median }}$ and $\varepsilon<\varepsilon_{\text {median }}$ groups, where $\varepsilon_{\text {median }}$ is the median $\varepsilon$ of the ground motion set. The DCM probabilities are then extracted separately for each of the ground motion groups and are depicted against each other in Figure 2. A closer distribution of points to $y=x$ line, in this figure, shows less significance of $\varepsilon$ parameter. A comparison between Figure 2(a) and (b) reveals that the significance of $\varepsilon$ parameter is a function of the over-strength provided in the frames. A less pronounced significance (higher correlation coefficient, $R^{2}$ ) is detected for frames with higher over-strength in which a narrower range of DCMs is observed.

A similar investigation is performed for evaluating the effect of pulse-like index, PI, of the ground motion records. The PI values of the 22 pairs of record incorporated in this study are computed using Eq. (3) and are tabulated in Table 2 along with other details about these records. Again, the DCM probabilities are extracted for two $\mathrm{PI}<\mathrm{PI}_{\text {median }}$ and $\mathrm{PI}>\mathrm{PI}_{\text {median }}$ groups of ground motions. The corresponding DCM probabilities are depicted versus each other (Figure 3) and their correlation coefficient is extracted. As demonstrated in Figure 3, the PI parameter has a more pronounced effect (denoted by smaller correlation) on DCM probabilities than the $\varepsilon$ parameter. As was the case for the $\varepsilon$ parameter, the significance of PI parameter depends on the provided over-strength and variety of the observed DCMs. Dependence of this significance on the employed design assumptions reveals that $S_{a}\left(T_{1}\right)$ parameter does not have the adequate efficiency to be used as the IDA's intensity measure. This is implied by the high sensitivity of DCM probabilities to the $\varepsilon$ and PI parameters.

The effect of number of employed records in estimating the DCM probabilities is assessed in the following by using record sets containing $7,14,22$, and 33 ground motion accelerations. The obtained DCM probabilities are again depicted against their 


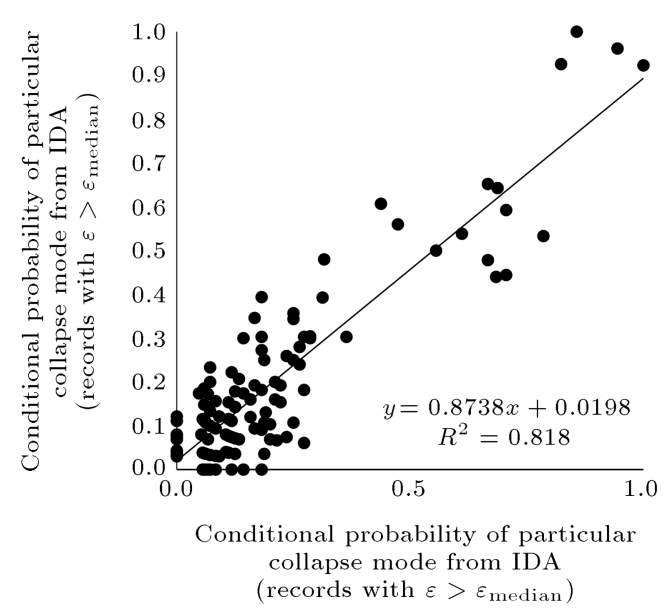

(a)

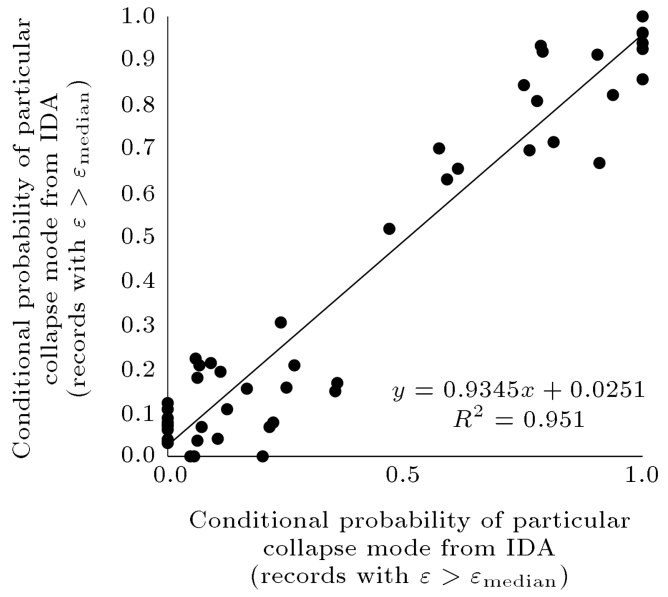

(b)

Figure 2. Probability of DCMs conditioned on collapse occurrence extracted from IDA; negative epsilon $(\varepsilon)$ records versus positive epsilon $(\varepsilon$ ) records: (a) Low over-strength structures and (b) high over-strength structures.

counterparts obtained through utilization of the full set (44 records) of ground motions. The related figures are omitted for the sake of brevity and the computed correlation coefficients are tabulated in Table 3. Here, a stronger correlation than that in the results obtained using full set of records denotes the higher adequacy of the utilized record number. Again, the number of records required for achieving a specific level of adequacy is shown to depend on the over-strength content.

Table 2. Details of selected ground motion histories.

\begin{tabular}{|c|c|c|c|c|c|c|c|c|}
\hline \multirow[t]{2}{*}{ ID } & \multirow[t]{2}{*}{$\begin{array}{l}\text { Magnitude } \\
\text { (M) }\end{array}$} & \multirow[t]{2}{*}{ Name } & \multirow[t]{2}{*}{ Station } & \multirow[t]{2}{*}{$\begin{array}{l}\text { Site class } \\
\text { (NEHRP) }\end{array}$} & \multirow[t]{2}{*}{$\begin{array}{l}\text { Fault } \\
\text { type }\end{array}$} & \multirow[t]{2}{*}{$\begin{array}{l}\text { Epicentral } \\
\text { distance }\end{array}$} & \multicolumn{2}{|c|}{$\begin{array}{c}\text { Pulse } \\
\text { indicator }\end{array}$} \\
\hline & & & & & & & 1-dir & 2-dir \\
\hline 1 & 6.7 & Northridge & Beverly Hills-14145 Mulhol 1 & $\mathrm{D}$ & Thrust & 13.3 & 0.97 & 0.96 \\
\hline 2 & 6.7 & Northridge & Canyon Country-W Lost Cany & $\mathrm{D}$ & Thrust & 26.5 & 0.80 & 0.00 \\
\hline 3 & 7.1 & Duzce, Turkey & Bolu & $\mathrm{D}$ & Strike-slip & 41.3 & 0.02 & 0.95 \\
\hline 4 & 7.1 & Hector Mine & Hector & $\mathrm{C}$ & Strike-slip & 26.5 & 0.47 & 0.41 \\
\hline 5 & 6.5 & Imperial Valley & DeltaU & $\mathrm{D}$ & Strike-slip & 33.7 & 0.00 & 0.00 \\
\hline 6 & 6.5 & Imperial Valley & El Centro Array \#11 & $\mathrm{D}$ & Strike-slip & 29.4 & 0.04 & 0.97 \\
\hline 7 & 6.9 & Kobe, Japan & Nishi-Akashi & $\mathrm{C}$ & Strike-slip & 8.7 & 0.00 & 0.00 \\
\hline 8 & 6.9 & Kobe, Japan & Shin-Osaka & $\mathrm{D}$ & Strike-slip & 46 & 0.08 & 0.01 \\
\hline 9 & 7.5 & Kocaeli, Turkey & Duzce & $\mathrm{D}$ & Strike-slip & 98.2 & 0.96 & 0.08 \\
\hline 10 & 7.5 & Kocaeli, Turkey & Arcelik & $\mathrm{C}$ & Strike-slip & 53.7 & 0.95 & 0.94 \\
\hline 11 & 7.3 & Landers & Yermo Fire Station & $\mathrm{D}$ & Strike-slip & 86 & 0.93 & 0.94 \\
\hline 12 & 7.3 & Landers & Coolwater & $\mathrm{D}$ & Strike-slip & 82.1 & 0.97 & 0.14 \\
\hline 13 & 6.9 & Loma Prieta & Capitola & $\mathrm{D}$ & Strike-slip & 9.8 & 0.00 & 0.03 \\
\hline 14 & 6.9 & Loma Prieta & Gilroy Array \#3 & $\mathrm{D}$ & Strike-slip & 31.4 & 0.00 & 0.92 \\
\hline 15 & 7.4 & Manjil, Iran & Abbar & $\mathrm{C}$ & Strike-slip & 40.4 & 0.33 & 0.01 \\
\hline 16 & 6.5 & Superstition Hills & El Centro Imp. Co. Cent & $\mathrm{D}$ & Strike-slip & 35.8 & 0.20 & 0.97 \\
\hline 17 & 6.5 & Superstition Hills & Poe Road (temp) & $\mathrm{D}$ & Strike-slip & 11.2 & 0.05 & 0.32 \\
\hline 18 & 7 & Cape Mendocino & Rio Dell Overpass-FF & $\mathrm{D}$ & Thrust & 22.7 & 0.02 & 0.00 \\
\hline 19 & 7.6 & Chi-Chi, Taiwan & CHY101 & $\mathrm{D}$ & Thrust & 32 & 0.92 & 0.93 \\
\hline 20 & 7.6 & Chi-Chi, Taiwan & TCU045 & $\mathrm{C}$ & Thrust & 77.5 & 0.00 & 0.96 \\
\hline 21 & 6.6 & San Fernando & LA-Hollywood Stor FF & $\mathrm{D}$ & Thrust & 39.5 & 0.58 & 0.8 \\
\hline 22 & 6.5 & Friuli, Italy & Tolmezzo & $\mathrm{C}$ & Thrust & 20.2 & 0.10 & 0.47 \\
\hline
\end{tabular}




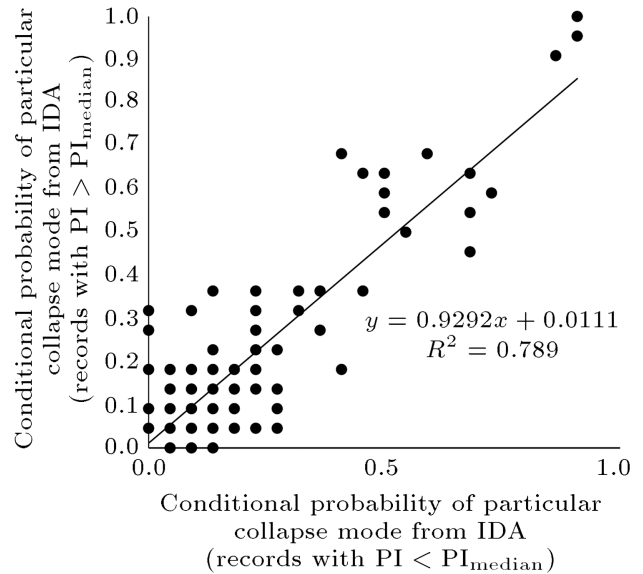

(a)

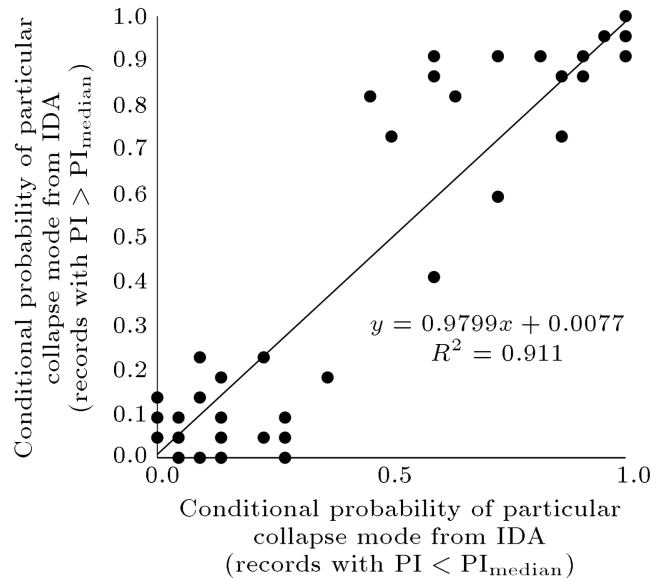

(b)

Figure 3. Probability of DCMs conditioned on collapse occurrence extracted from IDA; high pulse-index records versus low pulse-index records: (a) Low over-strength and (b) high over-strength.

Table 3. The correlation coefficients of regression analyses performed on the data obtained from different numbers of records required for DCM probabilities estimation.

\begin{tabular}{ccc}
\hline \multirow{2}{*}{$\begin{array}{c}\text { Number of } \\
\text { records }\end{array}$} & \multicolumn{2}{c}{ Correlation coefficient } \\
\cline { 2 - 3 } & $\begin{array}{c}\text { High } \\
\text { over-strength }\end{array}$ & $\begin{array}{c}\text { Low } \\
\text { over-strength }\end{array}$ \\
\hline 33 & 0.990 & 0.952 \\
22 & 0.981 & 0.940 \\
14 & 0.961 & 0.883 \\
7 & 0.920 & 0.721 \\
\hline
\end{tabular}

\section{DCM probabilities considering modeling uncertainties}

Response Surface-based Monte Carlo (RSMC) method, described in Section 6, is utilized for incorporation of modeling uncertainties into the derived DCM probabilities. According to the defined MRVs, (Beam Ductility, BD; Beam Strength, BS; Column Ductility, CD; and Column Strength, CS), 24 variations of each frame were generated following the Box-Wilson composite design method [15]. These variations included perturbing each MRV to positive and negative sides of its median, denoted respectively by + and - signs, while other MRVs were set to their median values. The 8 points generated in this way are called "star points" [15].
In addition, 16 "factorial points" [15] were deployed in which simultaneous changes were applied to the MRVs in negative and positive directions. The DCM probabilities obtained using the star point models for different over-strength levels of the 8-story building are illustrated in Figure 4.

As shown in Figure 4, the observed DCM probabilities are significantly affected by perturbing MRVs at their median values. The DCM probabilities obtained using perturbed models are depicted against their counterparts with median MRV values. $R^{2}$ values corresponding to the fitted linear trend-lines are extracted and presented in Table 4 considering both levels of over-strength. The smaller the presented $R^{2}$ values, the more effective the perturbed MRVs on the DCM probabilities.

According to the observed $R^{2}$ values (Table 4 ), the DCM probabilities experience the largest change (smallest correlation) by reducing ductility of the columns (CD). Ductility of columns has also shown in the previous research (e.g. [29]) to have the largest effect on collapse capacities of moment frames. An increase in CD level is not, however, as effective as its reduction. This asymmetric (or nonlinear as stated by Liel et al. [10]) effect is shown in Figure 5 through extracting Median Collapse Capacities (MCC) of 8-story frames for different column ductility ratios $\left(\mathrm{CD} / \mathrm{CD}_{\text {median }}\right) . \mathrm{MCC}$ is the intensity level (expressed here in terms of $S_{a}\left(T_{1}\right)$ ) in which $50 \%$ of ground motions drive the structure into collapse state. The

Table 4. The correlation coefficients of linear trend-lines fitted to the DCM probabilities data obtained from star point perturbations and median model.

\begin{tabular}{lccccccccc}
\hline & Over-strength & BD+ & BD- & BS+ & BS- & CD+ & CD- & CS+ & CS- \\
\hline \multirow{2}{*}{ Correlation coefficient, $\boldsymbol{R}^{\mathbf{2}}$} & High & 0.771 & 0.703 & 0.978 & 0.601 & 0.702 & $<0.5$ & 0.960 & 0.945 \\
& Low & 0.625 & $<0.5$ & 0.827 & 0.584 & 0.679 & $<0.5$ & 0.901 & 0.833 \\
\hline
\end{tabular}




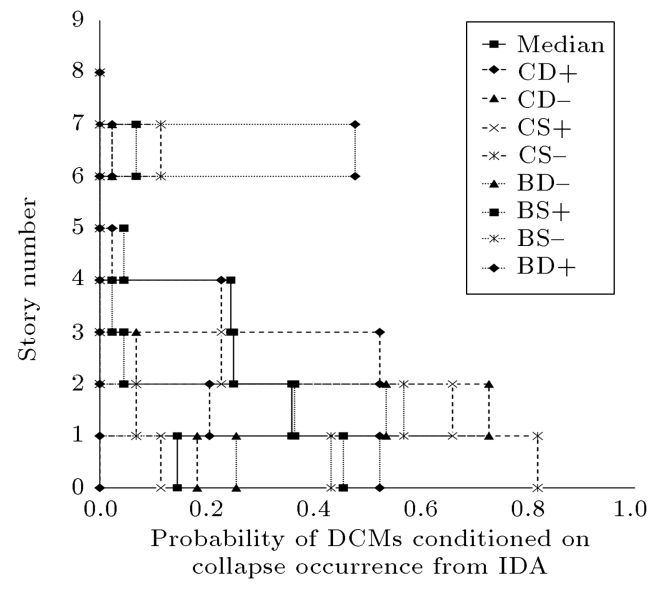

(a)

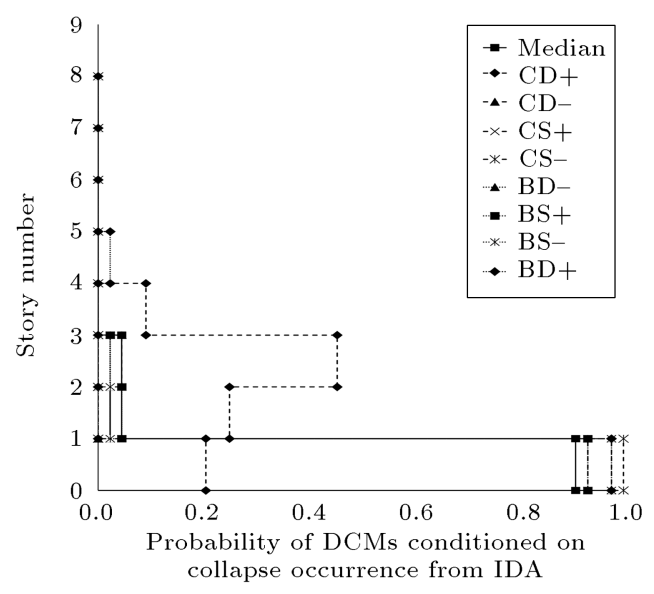

(b)

Figure 4. Probability of DCMs conditioned on collapse occurrence for star point perturbations: (a) Low over-strength structures and (b) high over-strength structures.

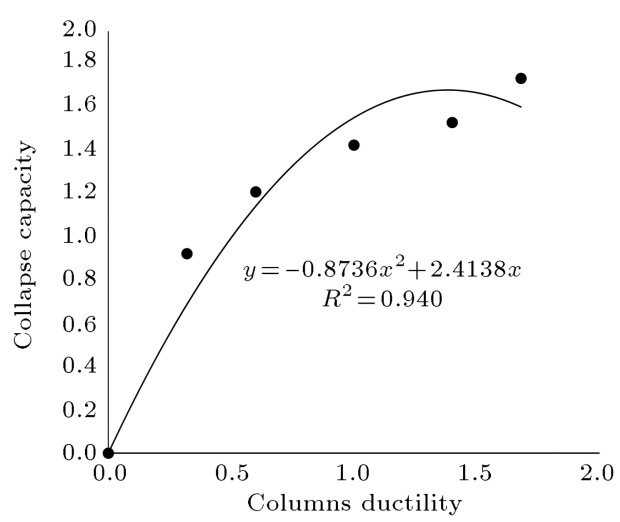

(a)

Figure 5. Collapse capacity versus CD of 8-story structure:

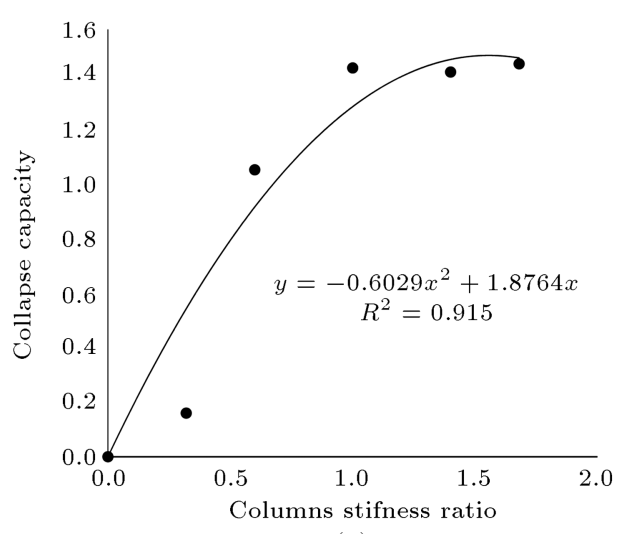

(a)

Figure 6. Collapse capacity versus CS of 8-story structure:

asymmetry of the MCC response to $\mathrm{CD}$ changes is illustrated by fitting a quadratic trend-line. This asymmetry is attributed by Liel et al. [10] to changes in the DCMs. However, this asymmetry is similarly observed for large over-strength models in which the number of DCMs is considerably reduced. A similar

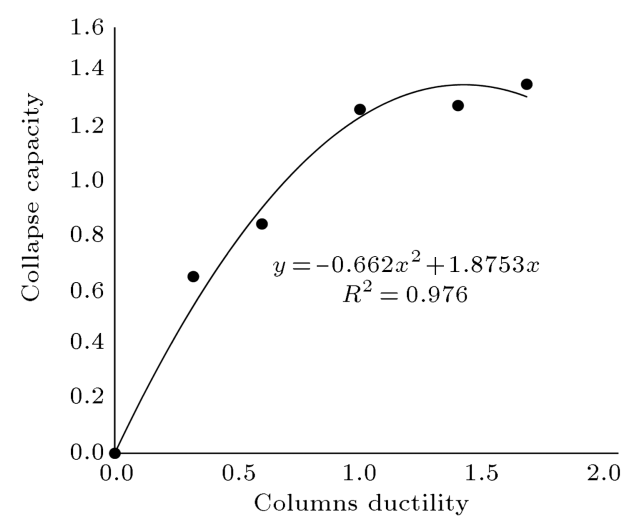

(b)

(a) Low over-strength frame and (b) high over-strength frame.

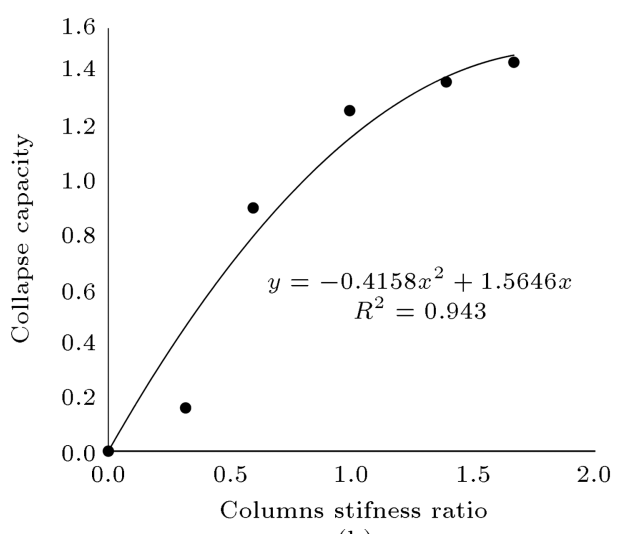

(b)

(a) Low over-strength frame and (b) high over-strength frame.

asymmetry can also be seen for Column Stiffness (CS) in Figure 6. The extent of this effectiveness is, however, low compared to the columns ductility. This is said by considering the fact that effectiveness of beams ductility is dependent on the over-strength level. Generally, the effectiveness of MRV perturbations 


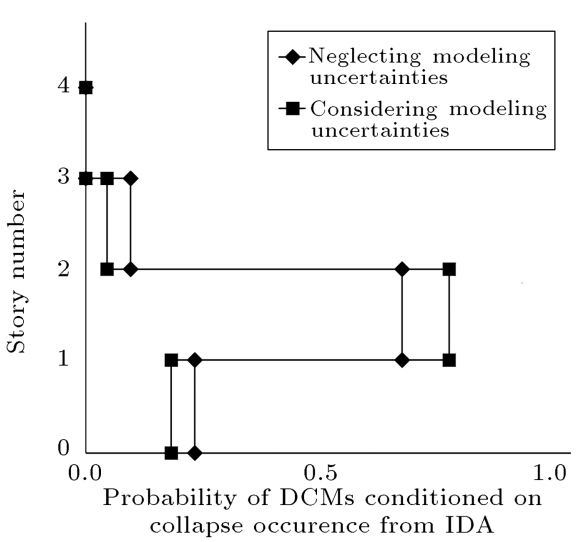

(a)

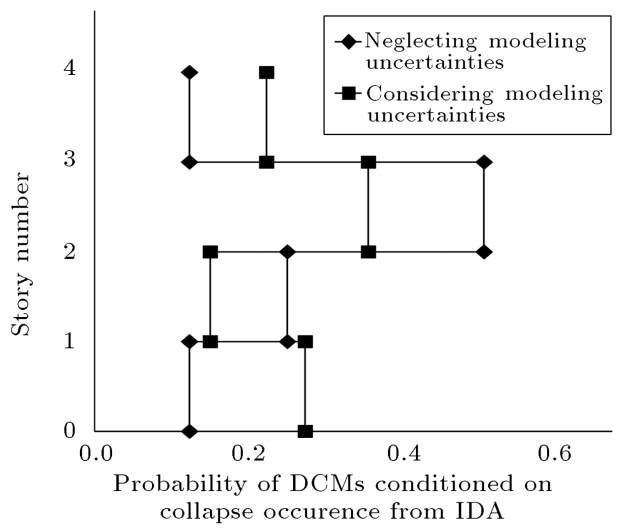

(b)

Figure 7. Probability of DCMs conditioned on collapse occurrence of 4-story structure incorporating modeling uncertainties: (a) High over-strength content and (b) low over-strength content.

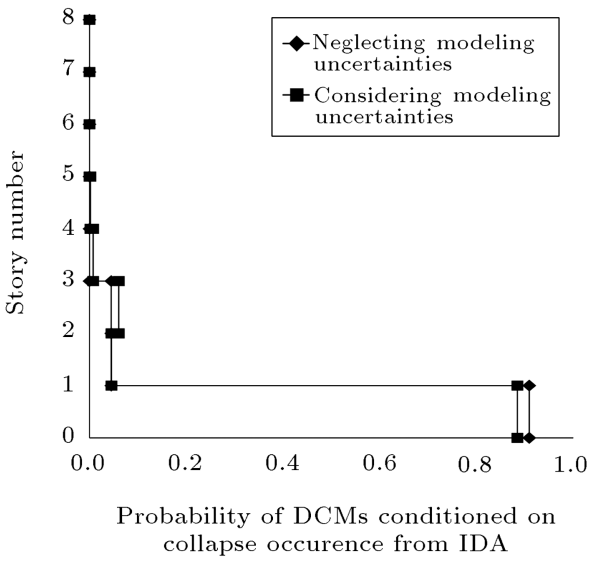

(a)

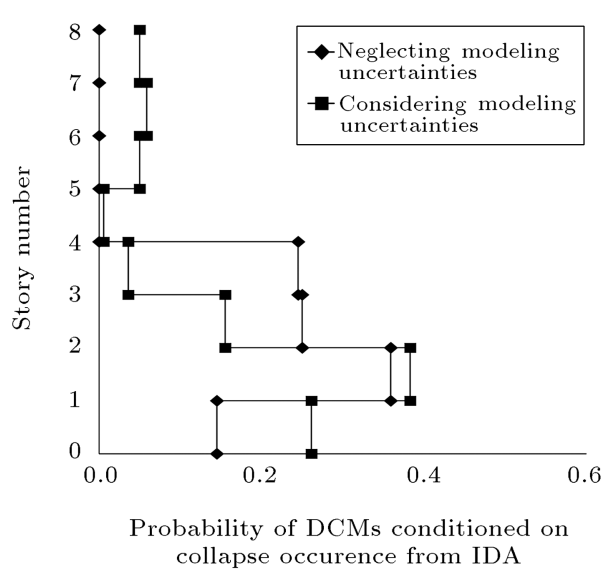

(b)

Figure 8. Probability of DCMs conditioned on collapse occurrence of 8-story structure incorporating modeling uncertainties: (a) High over-strength content and (b) low over-strength content.

decreases with increase in over-strength of frames. The strength-related parameters CS and BS follow trends similar to that presented for $\mathrm{CD}$ and $\mathrm{BD}$ variables.

To derive DCM probabilities in which modeling uncertainties are systematically considered, a quadratic surface is fitted to the sensitivity data. The general form of the regression equation is as follows:

$$
\begin{aligned}
\mathrm{TV}= & C 1 \times \mathrm{BS}+C 2 \times \mathrm{BS}^{2}+C 3 \times \mathrm{BD}+C 4 \times \mathrm{BD}^{2} \\
& +C 5 \times \mathrm{CS}+C 6 \times \mathrm{CS}^{2}+C 7 \times \mathrm{CD}+C 8 \times \mathrm{CD}^{2} \\
& +C 9 \times \mathrm{BS} \times \mathrm{BD}+C 10 \times \mathrm{BS} \times \mathrm{CS}+C 11 \times \mathrm{BS} \\
& \times \mathrm{CD}+C 12 \times \mathrm{BD} \times \mathrm{CS}+C 13 \times \mathrm{BD} \times \mathrm{CD}+C 14 \\
& \times \mathrm{CS} \times \mathrm{CD}+C 15+\mathrm{SE} \times \varepsilon .
\end{aligned}
$$

In this equation, $C 1$ to $C 15$ are regression coefficients and SE denotes the Standard Error resulting from discrepancies between observed and predicted values. This term is multiplied by the standard normal function, $\varepsilon$, to reflect the distribution of errors. As previously noted, the mean and standard deviation of the $\varepsilon$ function are respectively equal to 0 and 1 . Therefore, this term will not affect the mean of the predicted values while it increases their standard deviation by a value of SE. After computing the regression coefficients, the equations derived for different DCMs can substitute for IDA analysis. These equations provide a simpler and less expensive tool than IDA for computing DCM probabilities corresponding to randomly generated MRVs. Therefore, the established polynomials are utilized for random generation of 10,000 DCM probabilities following the Monte Carlo method. The average of the randomly generated probabilities is finally regarded as the value in which recordto-record and modeling uncertainties are considered concurrently. The DCM probabilities obtained with and without consideration of modeling uncertainties are depicted in Figures 7 to 10 for structures with different heights and various levels of over-strength. 


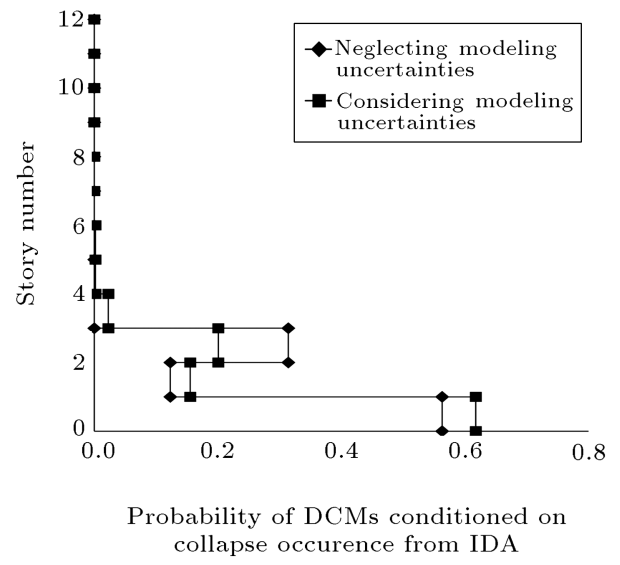

(a)

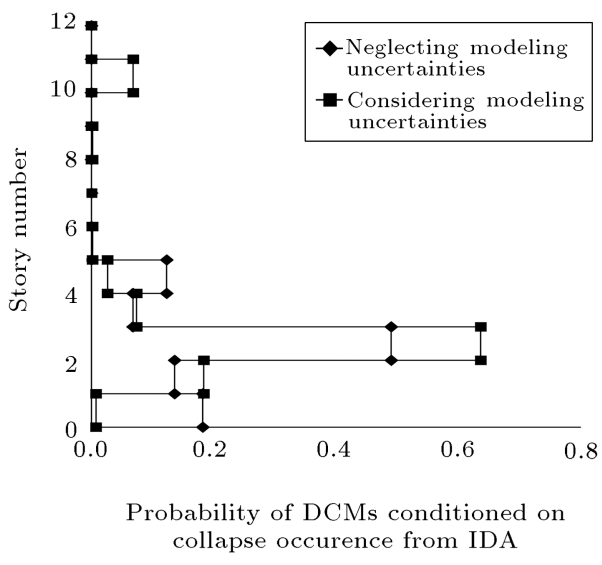

(b)

Figure 9. Probability of DCMs conditioned on collapse occurrence of 12-story structure incorporating modeling uncertainties: (a) High over-strength content and (b) low over-strength content.

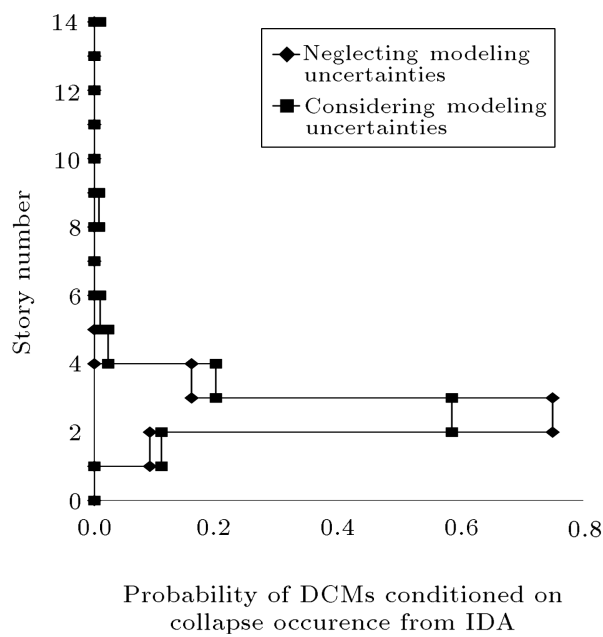

(a)

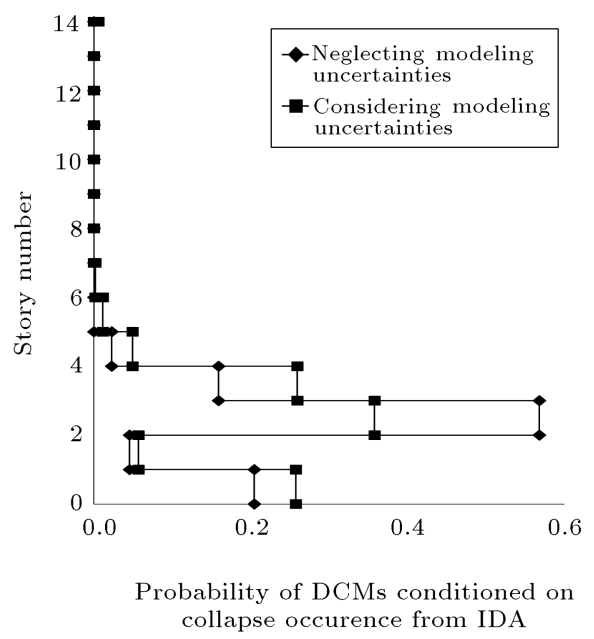

(b)

Figure 10. Probability of DCMs conditioned on collapse occurrence of 20-story structure incorporating modeling uncertainties: (a) High over-strength content and (b) low over-strength content.

As demonstrated by these graphs, modeling uncertainties affect the DCM probabilities obtained for both over-strength levels. This effect is, however, more pronounced for low over-strength buildings in which more varied DCMs are likely to occur. The extent of this effect is not, also, affected by the changes in the height of considered buildings.

\section{Conclusions}

The effect of Dominant Collapse Mechanisms (DCMs) on seismic losses of structures and the correlation between DCMs and collapse capacities of buildings have been currently addressed by seismic codes. To investigate the DCMs, two groups of RC structures with different levels of over-strength were considered. The DCMs of structures were then extracted through Incremental Dynamic Analysis (IDA) procedure incorporating Record-To-Record (RTR) uncertainties. The
DCMs probability conditioned on collapse occurrence were extracted and their sensitivity to parameters was assessed.

Afterwards, modeling uncertainties were introduced to the results using Response Surface-based Monte Carlo (RSMC) method. Strength and ductility of the beams and columns forming the structural systems were variably treated and 25 sensitivity IDA analyses were performed in which defined Random Variables (RVs) were perturbed at their median values. Considering the occurrence probability of various DCMs as the Target Variables (TVs), a response surface was defined using the 25 data points that correlated the TVs and the RV values. The established response surfaces were subsequently employed for computing the TVs corresponding to 10,000 randomly generated RVs. The arithmetic means of the generated TV values were finally considered as the values in which both RTR and modeling uncertainties were combined. 
The following conclusions can be pointed out for this study:

- The over-strength level resulting from design assumptions has a significant effect on the variety of DCMs observed throughout structures;

- Parameters such as spectral shape and pulse-like index of the records are effective on DCM probabilities. The degree of this effectiveness is a function of over-strength level and the variety of DCMs;

- In addition to the complete record set consisting of 44 records, DCM probabilities are obtained using smaller record sets. The proximity of smaller-sample DCM probabilities to the complete sample has also shown to depend on the over-strength level and the variety of likely DCMs;

- Any reduction in the ductility of columns has shown to significantly affect the observed DCM probabilities. Such observations have also been made for the beams, but to a lower extent. However, the uncertainties associated with the strength of the beams and columns leave minor effects on the observed DCM probabilities;

- In addition to the DCM probabilities, collapse capacities of the frames are extracted in terms of median $S_{a}\left(T_{1}\right)$ values corresponding to collapse state. For both low and large over-strength models, the observed capacities are remarkably affected by a reduction in variables while their increase leads to a less significant effect. Although previous studies suggested that this asymmetry was a result of changes in the DCMs, this asymmetry is observed for both groups of models in which the variety of DCMs is considerably different;

- The effect of modeling uncertainties on the observed DCM probabilities is significant and should not be disregarded, except for cases where a limited variety is observed for DCMs.

As a general conclusion, the RTR and modeling uncertainties are effective on the observed DCMs. This effect is more significant for structures with lower overstrength levels and wider variety of likely DCMs. The effectiveness of the uncertainties on the observed DCM probabilities is not influenced by the height of structures. The seismic losses must be, therefore, estimated by incorporation of RTR uncertainties and utilizing sufficient numbers of records selected appropriately.

\section{Acknowledgment}

The supports provided by the University of Guilan and Sharif University of Technology are gratefully acknowledged.

\section{References}

1. Takizawa, H. and Jennings, P.C. "Collapse of a model for ductile reinforced concrete frames under extreme earthquake motions", Earthquake Engineering \& Structural Dynamics, 8(2), pp. 117-144 (1980).

2. Bernal, D. "Instability of buildings during seismic response", Engineering Structures, 20(4), pp. 496-502 (1998).

3. Banazadeh, M. and Fereshtehnejad, S. "System reliability assessment of steel moment frames with different failure mechanisms using Bayesian Probability Network", in Proceedings, EuroDyn Conference, Leuven, Belgium, ISBN (2011).

4. FEMA, P695 "Quantification of building seismic performance factors", Federal Emergency Management Agency, Washington (2009).

5. Earthquake, G.P.-B. "The ATC-58 project: development of next-generation performance-based earthquake engineering design criteria for buildings" (2006).

6. Vamvatsikos, D. and Cornell, C.A. "Incremental dynamic analysis", Earthquake Engineering \& Structural Dynamics, 31(3), pp. 491-514 (2002).

7. Haselton, C.B., Baker, J.W., Liel, A.B. and Deierlein, G.G. "Accounting for ground-motion spectral shape characteristics in structural collapse assessment through an adjustment for epsilon", Journal of Structural Engineering, 137(3), pp. 332-344 (2009).

8. Tothong, P., Cornell, C.A. and Baker, J. "Explicit directivity-pulse inclusion in probabilistic seismic hazard analysis", Earthquake Spectra, 23(4), pp. 867-891 (2007).

9. Porter, K.A., Beck, J.L. and Shaikhutdinov, R.V. "Sensitivity of building loss estimates to major uncertain variables", Earthquake Spectra, 18(4), pp. 719-743 (2002).

10. Liel, A.B., Haselton, C.B., Deierlein, G.G. and Baker, J.W. "Incorporating modeling uncertainties in the assessment of seismic collapse risk of buildings", Structural Safety, 31(2), pp. 197-211 (2009).

11. Liel, A.B., Haselton, C.B. and Deierlein, G.G. "Seismic collapse safety of reinforced concrete buildings. II: Comparative assessment of nonductile and ductile moment frames", Journal of Structural Engineering, 137(4), pp. 492-502 (2010).

12. Haselton, C.B., Liel, A.B., Deierlein, G.G., Dean, B.S. and Chou, J.H. "Seismic collapse safety of reinforced concrete buildings. I: Assessment of ductile moment frames", Journal of Structural Engineering, 137(4), pp. 481-491 (2010).

13. Baker, J.W. and Cornell, C.A. "Spectral shape, epsilon and record selection", Earthquake Engineering \& Structural Dynamics, 35(9), pp. 1077-1095 (2006). 
14. Baker, J.W. "Quantitative classification of near-fault ground motions using wavelet analysis", Bulletin of the Seismological Society of America, 97(5), pp. 1486-1501 (2007).

15. Box, G.E. and Wilson, K. "On the experimental attainment of optimum conditions", Journal of the Royal Statistical Society, Series B (Methodological), 13(1), pp. 1-45 (1951).

16. Haselton, C.B., Assessing Seismic Collapse Safety of Modern Reinforced Concrete Moment Frame Buildings, Stanford University, Stanford (2006).

17. ACI 318-02. Building Code Requirements for Structural Concrete, ACI 318-02, American Concrete Institute, Detroit, Michigan (2002).

18. ASCE/SEI 7, Minimum Design Loads for Buildings and Other Structures, ASCE 7-02, American Society of Civil Engineers, Reston, Virginia (2002).

19. NIST, Selecting and Scaling Earthquake Ground Motions for Performing Response History Analysis, NIST/GCR 11-917-15, prepared by the NEHRP Consultants Joint Venture for the National Institute of Standards and Technology, Gaithersburg, Maryland (2011a).

20. Vian, D. and Bruneau, M., Experimental Investigation of P-Delta Effects to Collapse During Earthquakes, Multidisciplinary Center for Earthquake Engineering Research, buffalo (2001)

21. Vian, D. and Bruneau, M. "Tests to structural collapse of single degree of freedom frames subjected to earthquake excitations", Journal of Structural Engineering, 129(12), pp. 1676-1685 (2003).

22. Kanvinde, A.M. "Methods to evaluate the dynamic stability of structures-shake table tests and nonlinear dynamic analyses", in EERI Paper Competition 2003 Winner, Proceedings of the EERI Meeting, Portland, Citeseer (2003)

23. Mazzoni, S., McKenna, F., Scott, M.H. and Fenves, G.L., OpenSees Command Language Manual, Pacific Earthquake Engineering Research (PEER) Center (2006).

24. Ibarra, L.F., Medina, R.A. and Krawinkler, H. "Hysteretic models that incorporate strength and stiffness deterioration", Earthquake Engineering \& Structural Dynamics, 34(12), pp. 1489-1511 (2005).

25. Zareian, F. and Krawinkler, H., Simplified Performance-Based Earthquake Engineering, Stanford University, Stanford (2006).

26. Brunesi, E. and Nascimbene, R. "Extreme response of reinforced concrete buildings through fiber force-based finite element analysis", Engineering Structures, 69, pp. 206-215 (2014).

27. Brunesi, E., Nascimbene, R., Parisi, F. and Augenti, N. "Progressive collapse fragility of reinforced concrete framed structures through incremental dynamic analysis", Engineering Structures, 104, pp. 65-79 (2015).
28. Brunesi, E., Nascimbene, R. and Rassati, G.A. "Seismic response of MRFs with partially-restrained bolted beam-to-column connections through FE analyses", Journal of Constructional Steel Research, 107, pp. 3749 (2015).

29. Jalali, S.A., Banazadeh, M., Tafakori, E. and Abolmaali, A. "Seismic performance assessment of steel moment frames with generic Locally Reinforced connections", Journal of Constructional Steel Research, 67(8), pp. 1261-1271 (2011).

\section{Biographies}

Ehsan Tafakori obtained his BS degree in 2007 from Urumia University, Iran. He graduated from Amirkabir University, Tehran, in 2010, with an MS degree. In 2011, he was admitted into University of Guilan, Iran, as a $\mathrm{PhD}$ candidate. He is also a lecturer at the Islamic Azad University, Zanjan Branch, Iran. His main research interests are seismic performance evaluation and nonlinear finite element analysis of structures.

Saeid Pourzeynali received his MS degree in Structural Engineering in 1989 from Tehran University, Iran, and joined University of Guilan, Rasht, Iran, as a lecturer in the Department of Civil Engineering. In 1991, Dr. Pourzeynali obtained his PhD degree in Structural Engineering from IIT Delhi, India, and is currently at University of Guilan, Iran. His research interests span a wide range of specialized fields, including structural dynamics, earthquake engineering, random vibrations, reliability analysis, structural control and optimization, and dynamics of cable supported bridges. Dr. Pourzeynali has more than 25 years of experience in teaching and has supervised more than $30 \mathrm{MS}$ degree students. He has published more than 100 international journal and conference papers, and has received various awards, including "best research study on cable supported bridges" in 2004 from the ViceChancellor for Research at University of Guilan.

Homayoon E. Estekanchi is Professor of Civil Engineering at Sharif University of Technology, Tehran, Iran. He is member of the Iranian Construction Engineers Organization, ASCE, Iranian Inventors Association, and several other professional institutions. His research interests include a broad area of topics in structural and earthquake engineering, with special focus on the design of tall buildings and industrial structures, and the development of a new seismic analysis and design procedure called the "Endurance Time Method" and its application in various types of structures. 